\title{
Inés Quintero
}

Historiadora, profesora titular de la Universidad Central de Venezuela. Magister y doctora en Historia, individuo de número de la Academia Nacional de la Historia. Algunos de sus libros son: El ocaso de una estirpe (1989); El pensamiento liberal venezolano del siglo XIX (1992); Antonio José de Sucre. Biografía politica (1998); La conjura de los mantuanos (2002); La criolla principal (2003); Las mujeres de Venezuela. Historia minima (2003); El último marqués (Fundación Bigott, 2005); Francisco de Miranda (2006), y La palabra ignorada. La mujer testigo oculto de la bistoria en Venezuela (2008). Ha participado también en obras de referencia nacional e internacional y en numerosos libros colectivos y revistas especializadas en el campo de la historia.

\section{Resumen}

El artículo estudia los sucesos ocurridos en Caracas durante el año de 1808, a partir del análisis de las diferentes reacciones y las valoraciones contradictorias que suscita entre las autoridades peninsulares la propuesta juntista de los vecinos principales de la capital. A pesar de la diversidad de pareceres y de las argumenta- ciones expuestas por los involucrados en el conflicto, puede advertirse que todos actúan movilizados por un mismo objetivo: preservar el orden monárquico y evitar alteraciones ruinosas para la provincia. Será esta uniformidad de respuestas el signo característico del episodio juntista de Caracas en 1808.

Palabras clave:

Junta de Caracas, movimiento juntista, lealtad, orden monárquico. 


\title{
The Junta Movement and the Preservation of the Caracas Monarchical Order 1808
}

\author{
Inés Quintero
}

Historian, tenured professor at the Universidad Central de Venezuela. MA and Ph. D. in History, full member of the National Academy of History. Publications include: El ocaso de una estippe (1989); El pensamiento liberal venezolano del siglo XIX (1992); Antomio José de Sucre. Biografía política (1998); La conjura de los mantuanos (2002); La criolla principal (2003); Las mujeres de Venezuela. Historia minima (2003); El áltimo marqués (Fundación Bigott, 2005); Francisco de Miranda (2006), and La palabra ignorada. La mujer testigo oculto de la bistoria en Venezuela (2008). Has also contributed to national and international reference books as well as several books by groups of authors and history journals.

\begin{abstract}
This article examines the events that occurred in Caracas in 1808 on the basis of the various reactions and contradictory assessments elicited among the Spanish authorities by the junta's proposal submitted by leading residents in the capital. Despite the diversity of views and argu-

conflict, they can all be said to have been driven by a single objective: preserving the monarchical order and preventing disastrous changes for the province. This uniformity of responses is a characteristic feature of the junta episode in Caracas in 1808 .
\end{abstract} ments put forward by those involved in the

Key words:

Caracas, junta, junta movement, loyalty, monarchical order. 


\title{
El movimiento juntista y la preservación del orden monárquico, Caracas, 1808
}

\author{
Inés Quintero
}

\section{INTRODUCCIÓN}

En América, las primeras noticias sobre la abdicación de Carlos IV y Fernando VII en Bayona y la imposición de José Bonaparte como nuevo rey de España se recibieron en la segunda semana de julio. En las semanas y meses siguientes, la respuesta en las principales ciudades, villas y pueblos de ultramar fue de rechazo a la usurpación francesa y de lealtad a Fernando VII. El suceso generó un amplio debate, de uno y otro lado del Atlántico, producto de la crisis política que constituía el vacío de poder ocasionado por las abdicaciones de $\mathrm{Ba}-$ yona. La respuesta, tanto en la península como en América, fue la misma: ausente el rey la soberanía recaía en el pueblo. En consecuencia, se procedió, primero en España y luego en América, a constituir juntas que fuesen las depositarias de la soberanía mientras el rey permanecía ausente.

En el caso de América, el proceso de erección de juntas fue diverso y con resultados diferentes. En algunos casos, se logró la constitución de juntas como ocurrió en Nueva España, en Quito, en Chuquisaca y en La Paz. En otros lugares se propuso la erección de juntas, sin que se lograse el cometido, como sucedió en Caracas y en Buenos Aires. En otras provincias y ciudades sencillamente se reconoció la autoridad de la Junta de Sevilla y después de la Junta Central del reino. ${ }^{1}$ Las respuestas de las autoridades frente a cada uno de estos movimientos también fueron diferentes y estuvo sujeta a las condiciones particulares y a los sucesos acaecidos en cada lugar.

En Caracas, si bien no se logró instalar la Junta, se le abrió proceso a los juntistas quienes, al final, fueron absueltos. El proceso, desde sus inicios hasta su culminación, generó un fuerte debate entre las autoridades de la monarquía dividiéndolos en sus apreciaciones y juicios sobre el hecho. Este artículo tiene como propósito analizar la reacción de las autoridades monárquicas frente al proyecto juntista de Caracas a fin de conocer las contradicciones y preocupaciones que suscitó el movimiento, así como la manera de atenderlo por parte de quienes tenían a su cargo la preservación del orden monárquico en la provincia de Venezuela.

\section{EL SOMETIMIENTO DEL MOVIMIENTO JUNTISTA EN AMÉRICA}

En la mayoría de las provincias de ultramar hubo elocuentes expresiones de leal-

${ }^{1}$ Sobre el movimiento juntista americano véanse Chust, Edlasion, 1992, y Rodríguez, Independencia, 1998. 
tad a la monarquía y al legítimo y único rey de España: don Fernando VII. También, en muchas de ellas, las manifestaciones de lealtad se vieron acompañadas de iniciativas cuyo objetivo era seguir el ejemplo de España y constituir juntas encargadas de velar por la seguridad del reino y proteger los intereses de Fernando VII de este lado del Atlántico. En todos los casos, los proyectos e intentos de juntas fueron interpretados como una tentativa independentista, en franca contravención a la lealtad y fidelidad a la monarquía y no como una expresión del espíritu pactista que los inspiró.

Quienes sometieron al movimiento juntista americano representaban a los sectores más próximos al absolutismo y, tanto en España como en América, consideraban que la crisis ocasionada por la invasión de los franceses, en ningún caso, podía dar lugar a cambios políticos en el gobierno y funcionamiento de la monarquía, mucho menos podía permitirse que ocurriesen mudanzas en las provincias de ultramar, las cuales no gozaban de las mismas prerrogativas que las provincias peninsulares ni se encontraban en una situación similar.

En Nueva España, la instalación de la junta por iniciativa del Cabildo de la ciudad de México y presidida por el virrey José de Iturrigaray fue cuestionada desde el primer momento por la Real Audiencia. El criterio del máximo tribunal era compartido por el arzobispo, el gran inquisidor, los delegados de la Junta de Sevilla y los sectores conservadores que veían con desconfianza la introducción de novedades en el gobierno del virreinato. Finalmente, consiguieron el apoyo de la guardia del palacio y del cuerpo de la artillería y comprometieron en la acción a don Gabriel Yermo, comerciante y terra- teniente español de gran prestigio y considerable caudal, quien aceptó convertirse en director del movimiento contra la iniciativa juntista, persuadido de que la creación de una autoridad autónoma minaba la subordinación a la metrópoli.

La noche del 15 de septiembre de 1808 fue asaltada la vivienda del virrey y este fue conducido ante el gran inquisidor y de allí al convento de los betlemitas, donde quedó incomunicado. Su esposa e hijos también fueron extraídos del palacio y encerrados en el convento de San Bernardo. Unos días más tarde, el grupo familiar salió rumbo a España.

El virrey fue sometido a juicio en España por los cargos de peculado y traición, condenado por el primero y absuelto por el segundo. Los principales capitulares incursos en el movimiento fueron arrestados. Concluyó así la tentativa del Cabildo de México.

En la ciudad de Chuquisaca el movimiento juntista también fue sometido. Una fuerza armada enviada por el virrey Santiago de Liniers desde Buenos Aires ocupó la ciudad; la junta fue disuelta y los autores y cómplices del movimiento fueron desterrados. En La Paz, ocurrió otro tanto. El virrey de Perú, José Fernando de Abascal, mandó un ejército al mando de José Manuel de Goyeneche, comisionado de la Junta de Sevilla, para disolver y acabar con el movimiento. La ciudad de La Paz fue tomada el 25 de octubre de 1809; Goyeneche ordenó perseguir a todos aquellos que habían huido hacia la selva y dispuso la preparación de los instrumentos de tortura para martirizar al vecindario. Los principales promotores fueron encontrados y ajusticiados.

También fue sometida de manera violenta la Junta Gubernativa de Quito, 
constituida el 9 de agosto de 1809. El virrey de la Nueva Granada envió una columna de 300 hombres desde Santafé de Bogotá y otra de 200 soldados desde Panamá. El virrey de Perú hizo otro tanto y declaró "nula y ridícula" la autoridad de la junta. Un ejército de 500 hombres se embarcó desde Perú rumbo a Guayaquil.

El 4 de diciembre fueron sometidos a prisión los principales promotores del movimiento y se les abrió causa. El juicio fue presidido por el oidor Fuentes Amar, y el fiscal solicitó la pena de muerte para los principales cabecillas. El 2 de agosto de 1810 fueron ejecutados.

Todos los movimientos fueron sometidos, unos con mayor violencia que otros, aun cuando todos se hicieron en nombre del rey cautivo, en defensa de la religión y la patria e inspirados en el espíritu pactista de las leyes del reino.

En el caso de Caracas hubo una rápida respuesta por parte de las autoridades. Todos los involucrados en la propuesta juntista fueron perseguidos y sometidos a prisión; sin embargo, el desenlace no tuvo las violentas consecuencias de Quito o La Paz, como veremos a continuación.

\section{UN PRETEXTO PARA ASPIRAR}

\section{A LA INDEPENDENCIA}

Las noticias de las abdicaciones de Bayona llegaron a Caracas el 15 de julio de 1808; inmediatamente se procedió a celebrar la ceremonia de la jura del monarca y, en los días siguientes, se discutió cómo atender la emergencia ocasionada por la crisis política que se vivía en el reino. El 27 de julio el capitán general le solicitó al Ayuntamiento la elaboración de un proyecto de junta, a los dos días estaba listo el do- cumento. Sin embargo, esta primera iniciativa no tuvo consecuencias ya que, al comenzar el mes de agosto, llegaron a Caracas los comisionados de la Junta de Sevilla y las autoridades decidieron reconocer la autoridad de esta junta, aun cuando el Cabildo y algunas personalidades manifestaron sus reservas al respecto.

Antes de concluir el año, durante el mes de noviembre, un grupo de vecinos principales retoma la propuesta del capitán general y le dirige una representación solicitándole la constitución de una junta que fuese la depositaria de la soberanía en ausencia del rey. El documento tiene fecha de 22 de noviembre de 1808, está firmado por 45 vecinos principales entre criollos y peninsulares y sigue de cerca el contenido de las proclamas y pronunciamientos de las juntas que se erigieron en la península. Se trata de un manifiesto de fidelidad a la corona; toda su argumentación se remite a la doctrina fundamental del reino, y a la defensa de sus pilares constitutivos: la religión, la patria y el rey; su propósito era preservar la integridad de la monarquía.

Ia respuesta, como ya se dijo, fue abrir causa contra los promotores de la propuesta. El procedimiento estuvo a cargo del regente interino de la Real Audiencia de Caracas, Joaquín Mosquera y Figueroa, oriundo de Popayán y defensor irrestricto de la legalidad y el orden monárquico.

Mosquera conocía de cerca la sociedad caraqueña. Había llegado a Venezuela el 2 de febrero de 1805 , enviado por la corona a realizar una inspección directa de la Real Audiencia de Caracas mediante el procedimiento de una visita, a fin de conocer las irregularidades y el desorden en la administración de justicia en la provincia, según constaba en diferentes informes recibidos por el Consejo de Indias. 
Durante tres años investiga de manera acuciosa, convoca testigos, conoce las denuncias de corrupción, reconstruye las redes y vínculos de lealtad que unen a ministros y vecinos, averigua la vida y movimientos de todos los implicados en las denuncias, destituye funcionarios $y$, al concluir su labor en octubre de 1808 , solicita que se le permita regresar a México, lugar en el cual se encontraba al momento de ser enviado como regente visitador de la Audiencia de Caracas.

El resultado del informe es contundente: arbitrariedades en el desempeño de las funciones del alto tribunal, tráfico de influencia de los magistrados, vida desarreglada de los jueces, manejos dolosos en la administración de justicia, incompetencia en la resolución de los casos y corruptelas de la más variada índole. Debido a su labor fueron removidos de sus cargos tres ministros. ${ }^{2}$

Para un funcionario como Mosquera quien, por órdenes de la corona, se encontraba en la ciudad de Caracas para velar por el buen orden y la normalización en la administración de justicia, cualquier intento de perturbar la tranquilidad de los territorios a su cargo tenía que hacerlo actuar de manera inmediata.

Cuando tiene conocimiento de las primeras reuniones y conciliábulos que tienen lugar en la ciudad para promover la redacción y firma del documento, se ocupa de vigilar la casa de José Félix Ribas, uno de los cabecillas del movimiento, con la orden expresa de tomar nota de todo aquel que entrara o saliera de la casa y de escuchar cualquier comentario que se colara hacia fuera por las ventanas. Todas las noches, durante tres días, el oficial de vi-

${ }^{2}$ Albornoz, Visitat 1987. sita don Gregorio López de Briñas, y el escribano real, José María Moya, se esconden tras las esquinas para dar cuenta al regente visitador de las peripecias de los conjurados.

Los informes son detallados y dan cuenta de hombres embozados en sus capas que entran y salen. Un negro en el zaguán de la casa de don José Félix Ribas hace las funciones de espía y de portero. Ven salir apresuradamente a un hombre con bastón, otro con capa acompañado de una mujer, dos hombres también con capa, pero no logran reconocer a ninguno. Se oye murmullo de gente en la sala y puede verse que hay luz por las rendijas de las ventanas. El sonido de una de las voces les hace sospechar que entre los asistentes se encuentra don Juan Jerez de Aristeguieta.

Luego de perseguir al hombre del bastón se percatan de que se trata de José Félix Ribas. En el zaguán de la casa de enfrente, perteneciente a don Feliciano Palacios, alférez real del Ayuntamiento capitalino, pudieron identificar a don Pedro Palacios y Sojo, alguacil mayor de la Real Audiencia. Todo esto ocurría en la noche del 21 de noviembre.

Al día siguiente, en horas del mediodía, atestiguan haber visto reunirse en la casa de don Juan Jurado, teniente de gobernador y auditor de guerra de la provincia, a don Antonio Fernández de León, al marqués del Toro y a José Félix Ribas. Esa misma noche, cerca de las doce, el marqués del Toro, alumbrado con un farol y en compañía de dos sirvientes, se encontraba en las inmediaciones de la casa de Ribas. Y al día siguiente, también en la noche, vieron a Vicente Ibarra entrar a la casa de Ribas y a Mariano Montilla con capa blanca y sombrero de copa alta "ob- 
servando a las gentes que pasaban y mirando con atención para todas partes".

El día 24 de noviembre compareció voluntariamente don Pedro de la Mata, natural de la provincia de Soria de Castilla la Vieja, para manifestar que él al igual que muchos hombres de bien, vecinos honrados

han creído y cree que el verdadero aunque oculto objeto de los autores de dicho proyecto, no ha sido otro que el de excitar una conmoción popular, destruir las autoridades legítimamente constituidas, que todos los buenos vecinos hacen vanidad de respetar, seguidamente establecer un gobierno independiente $[\ldots]$ que la mala fe y no el deseo de lo más conveniente a la monarquía era la base del indicado proyecto. ${ }^{1}$

Consideraba conveniente que el gobierno procediera a la aprensión de los que resultasen culpados ya que si no se tomaban medidas "prontas, ejecutivas y eficaces, tendrá la cosa muy malas resultas".

En una ciudad como Caracas difícilmente podían pasar desapercibidas las entradas y salidas de una casa a la otra de los más conocidos sujetos de la sociedad caraqueña, envueltos en sus capas y en horas

; "Testimonios de Gregorio López Briña y don José María Mora en el expediente de las diligencias preliminares que se practicaron y las cuales obligaron a celebrar el acuerdo del 24 de noviembre". Conjuración, 1968, pp. 100-106. Esta obra publicada en dos volúmenes contiene el expediente completo de causa, todas las citas son tomadas de la misma publicación, destacando en cada caso, el título del documento tal como aparece en la obra referida.

" "Declaración de don Pedro la Mata", 24 de noviembre de 1808 , en ibid., p. 109.

5 "Declaración de Pedro de la Mata", en ibid., p. 110. de la noche. En la pequeña ciudad, de escaso número de manzanas, todo el vecindario sabía quién vivía en cada casa, de igual manera, las rutinas de la capital eran más o menos las mismas. Era, pues, absolutamente inevitable que la agitación de los vecinos principales generara todo tipo de rumores y comentarios y que, por tanto, despertara la suspicacia de las autoridades.

El 24 de noviembre se reunieron en la casa del presidente gobernador y capitán general, don Juan de Casas, el regente visitador Mosquera y Figueroa, don Antonio Julián Álvarez, oidor de la Real Audiencia de Caracas, don Francisco Berrio, fiscal de la Real Hacienda y don Francisco Espejo, oidor honorario de la Real Audiencia y encargado de las fiscalías en lo civil y criminal.

El motivo de la reunión era tratar la "grave alteración" que se notaba en la ciudad cuyo origen era

haberse esparcido la vo $z$ que varios vecinos de ella pretenden formar una Junta Suprema, y haber llegado a comprender, y divulgar que semejante proyecto era encaminado a apoderarse del gobierno, luego que estuviera constituida, quitando y separando después las autoridades establecidas y poniendo en su lugar otras para lograr de este modo la independencia y separación de la metrópoli."

Después de ver las actuaciones adelantadas por el regente Mosquera, de estudiar la representación que con oficio de esa misma fecha hicieron llegar al gobernador el conde de Tovar, el marqués del

6 "Acta de la reunión del 24 de noviembre en casa del gobernador Juan de Casas", en ibid., p. 118. 
Toro y Antonio Fernández de León, teniendo en consideración "los graves y peligrosos movimientos a que se halla expuesta esta ciudad", habiendo reflexionado detenida y maduramente sobre el carácter y circunstancias de los que habían firmado la referida representación y con el conocimiento en que se hallaban de las especies esparcidas relativas a los mismos sujetos, resolvieron:

1. Arrestar en sus respectivas casas al marqués del Toro, al conde de San Javier y a don Antonio Fernández de León.

2. Arrestar en los cuarteles que el señor presidente dispusiera a don José Félix Ribas, a los abogados don Nicolás Anzola y don Vicente Tejera, a don Mariano Montilla, don Francisco de Paula Navas, don Juan Sojo y a los hermanos don Martín y don José Tovar.

3. Arrestar en los cuarteles mientras se les recibía declaración y luego confinarlos fuera de la ciudad a don Pedro Palacios quien debía ser enviado a Curiepe; a los abogados don Ignacio y Antonio Nicolás Briceño Méndez quienes serían remitidos luego a la Sabana de Ocumare; a don Francisco Antonio Paul y don Juan Jerez Aristeguieta quienes serían confinados en Aragüita; a don Juan Nepomuceno Ribas cuyo destino sería Guatire; a don José María Uribe a la costa de Ocumare; a don Isidoro Quintero, don Domingo Galindo y don Narciso Blanco para Puerto Cabello; a don Antonio Estéves para Tacarigua, a don Tomás Montilla a Baruta, a don Vicente Ibarra al pueblo de Charallave y a don Francisco de la Cámara para la Guaira. ${ }^{7}$

En el caso de don Antonio Fernández de León, la respuesta fue más contundente. El 5 de diciembre, luego de recibirle

${ }^{7}$ Ibid., pp. 118-119. declaración y en atención a "justas, graves y urgentes consideraciones" se resuelve enviarlo bajo partida de registro a disposición de la Suprema Junta Central Gubernativa del Reino establecida en Aranjuez. Debía embarcarse en el bergantín San José y las Ánimas, próximo a salir del puerto de la Guaira. Mientras esperaba la salida del barco, debía permanecer en uno de los castillos de la plaza sin permitírsele otra comunicación que la necesaria para los arreglos de su viaje. Y en caso de que estuviese ocupada la cámara del bergantín con algunos pasajeros, debían tomarse las providencias para hacerle lugar así fuese desembarcando el equipaje de los viajeros. ${ }^{8}$ Era preciso, a toda costa, sacarlo de la provincia cuanto antes.

El informe que envía el regente Mosquera a España está fechado el 26 de noviembre, dos días después de la prisión y confinamiento de los implicados en la representación.

En el documento hace mención a un primer informe del 21 de noviembre en el cual daba a conocer el estado de agitación e intranquilidad que se vivía en la ciudad, por la pretensión de varias personas principales de que se estableciese una Junta Suprema lo que había motivado fuesen vigilados en cada uno de sus movimientos y operaciones.

Fue así como, el día 24, se le presentó la "feliz oportunidad" de proceder a las muy importantes actuaciones para impedir lo que se intentaba efectuar en esta capital por "los mal contentos del gobierno y de la dependencia de estas provincias a la península".

Su propósito era "impedir la ruina que amenazaba" a la provincia y conservarla

${ }^{8}$ Ibid., p. 14. 
en tranquilidad y buen orden; pretendía, al mismo tiempo, cortar los daños que "tan eminentemente amenazaban" aun a los mismos pretensores de la junta, luego de que las noticias esparcidas por la ciudad generaran la mayor fermentación en gentes de todas las clases.

En su concepto la constitución de una junta era "un pretexto que se tomaba para aspirar a la independencia", así lo expresaba en el título de la comunicación que le envía a la Suprema Junta de Gobierno del Reino."

Mosquera actuaba por vía extraordinaria en combinación con el capitán general y uno solo de los ministros de la audiencia, el oidor don Juan Antonio Julián Álvarez. Esta determinación, obviamente, tenía su origen en la desconfianza que le suscitaban los demás ministros de la Real Audiencia a quienes les había correspondido investigar como visitador desde su llegada a Caracas, durante los últimos tres años.

En virtud de ello, en el mismo expediente que envía a España, aclara su determinación de no pasar información ni involucrar a ningún otro de los ministros de la Audiencia ya que, de ser así, "quedarían frustrados todos nuestros deseos nacidos únicamente de la fidelidad que debemos a vuestra majestad, como sucede cuando en estas materias no se puede contar con el secreto". ${ }^{10}$

"Joaquín de Mosquera Figueroa. "Informe sobre la prisión efectuada en varios sujetos de la primera representación de esta ciudad, con motivo del proyecto de establecer en ella una Junta Suprema que se ha creído era un pretexto que se tomaba para aspirar a la independencia si se llegaba a establecer", 26 de noviembre de 1808 , en itrid., pp. 800-801.

11) Itid., p. 801 .
Pero no solamente eran los ministros de la Real Audiencia quienes despertaban la suspicacia del regente, sino también otros dos altos funcionarios de la administración peninsular. Don Antonio López de Quintana, ex regente de la audiencia y ministro electo para el Consejo de Indias y don Juan Jurado, teniente de gobernador y auditor de guerra de la provincia.

En relación con el primero, la sospecha tenía su origen en "la íntima e inseparable unión de tantos años con don Antonio de León". En consecuencia "nadie puede creer deje de haber entrado en el mismo proyecto de León". También porque, según había expuesto el capitán general, le había causado mucha extrañeza que López de Quintana, durante todos estos acontecimientos, no se hubiese acercado a su casa a comentarle sobre ellos. Pensaba Mosquera que el disimulado y artificioso proceder de Quintana aconsejaba sacarlo de la provincia ya que este sujeto era el que influía y sostenía las máximas e intenciones que propagaba Fernández de León. ${ }^{11}$

En cuanto a don Juan Jurado, al igual que Quintana, se encontraba complicado en el movimiento, según se desprendía de la declaración de los testigos. Si Quintana era cercano a Fernández de León, en el caso de Jurado se daba una situación similar con José Félix Ribas, quien era su amigo íntimo y compadre y a quien le debía una cuantiosa hacienda de café, la cual cultivaba y mantenía a pesar de las prohibiciones expresas de las leyes en esta materia. Jurado también era amigo cercano de Fernández de León, del marqués del Toro y de los hermanos Montilla, todos ellos firmantes de la petición.

"Ilid., pp. 809-810. 
Su recomendación era que Jurado fuese extrañado de la provincia porque a su connivencia con los "revoltosos" se sumaba el odio general que se había granjeado en esta ciudad por su conducta ministerial. ${ }^{12}$

Los cuidados de Mosquera y su inquebrantable determinación de cortar de raíz la promoción de la junta, incluyendo a los funcionarios peninsulares que pudiesen estar en combinación con los juntistas, obedecía a su firme propósito de impedir la introducción de novedades en el gobierno de la provincia; era consistente con sus primeras opiniones y guardaba clara correspondencia con la respuesta que se había dado en México contra el intento de Iturrigaray y los capitulares de la ciudad.

Mosquera, al igual que muchos convencidos absolutistas en ambas riberas del Atlántico, no veía motivo alguno para que en las provincias se introdujesen cambios y, si esto ocurría, no podía interpretarse de otra manera: la intención de sus promotores era subvertir el buen orden y propiciar la independencia.

Era inevitable que, frente a la magnitud de los sucesos y en virtud de la complejidad y profundidad del debate político que generó la crisis política de la monarquía, las opiniones se encontraran divididas, no solamente en la península sino en todo el vastísimo imperio español. Caracas no fue una excepción.

Los ministros de la Real Audiencia, el consejero Quintana y el teniente de gobernador, si bien no se pronunciaron ni firmaron la representación, disentían abiertamente del criterio de Mosquera y estaban en desacuerdo con la persecución y prisión de los juntistas. Sus reservas y argumentaciones se exponen a continuación.

12 Ibid., p. 810 .

\section{FUNESTAS CONSECUENCIAS}

PARA LA PROVINCIA

Cada uno de ellos en documentos diferentes y como iniciativas de carácter individual se dirige a las autoridades del reino para exponer su preocupación por las consecuencias que podrían acarrear el abuso y la arbitrariedad del regente Mosquera. Todos coincidían en que las actuaciones de Mosquera podrían generar una situación peligrosa de tensión y conflicto entre los vecinos principales y las autoridades de la monarquía en aquellos territorios que, sin la menor duda, resultarían funestas para el futuro de la provincia.

Don Antonio López de Quintana fue uno de los primeros en dirigirse a la Junta Central del Reino para exponer sus reservas respecto a lo que estaba ocurriendo en la ciudad de Caracas.

Quintana había sido, hasta 1804, decano regente de la Real Audiencia de Caracas, ese mismo año fue ascendido para el mismo cargo en la Real Audiencia de Santa Fé, sin embargo, no viajó inmediatamente a esa ciudad en vista de que debía permanecer en Caracas mientras Mosquera practicaba la visita. Mientras se ejecuta la visita es electo para el Consejo de Indias en España. Finalmente viaja a la península en 1809 , cuando concluye el trámite de Mosquera y cesan temporalmente las discordias que se suscitaron por los sucesos de noviembre de 1808 .

El ex regente Quintana tenía sobrados motivos contra el visitador Mosquera. En 1807, en su informe, Mosquera había levantado 36 cargos en su contra por negligencia y descuido en el desempeño de sus funciones como regente de la Audiencia de Caracas. Cada uno de los cargos fue respondido por Quintana en una detalladísima y 
larga representación al Rey. ${ }^{13}$ Si bien el informe de Mosquera no modificó su elección como ministro del Consejo de Indias, había sido, sin lugar a dudas, un episodio particularmente molesto en la carrera de Quintana.

Es así como, el 28 de noviembre, dirige una representación a España en la cual manifiesta su parecer respecto a la iniciativa de los principales. Dice Quintana:

Ninguna de sus provincias ha tenido ni manifestado mayor ardor que estas a la primera noticia del atroz insulto hecho a la real persona de vuestra majestad y todas las de su real casa por el emperador de los franceses, ni es dable escribir una idea exacta de los deseos ardientes de estos vasallos para concurrir por todos los medios de que son capaces al desagravio de vuestra majestad y de la nación entera.

Pesarosos de la falta de actividad, algunos de los primeros hombres de esta capital creyeron que no era remediable sino por el medio de la formación de una junta, a cuya cabeza estuviese el gobernador y trabajase con la actividad de que han dado ejemplo las de España. Trataron de ese pensamiento con otros muchos de las casas principales: le extendieron por escrito; le llevaron al mismo gobernador, el cual le estimó oportuno como consiguiente al pensamiento que él había comunicado antes al Ayuntamiento, por medio de oficio que le propuso y extendió el regente interino de la Audiencia don Joaquín de Mosquera, y se la presentaron firmado por muchos. ${ }^{1 /}$

13 "Representación al rey de don Antonio López de Quintana, sobre los cargos determinados por el visitador Joaquín Mosquera y Figueroa", 20 de octubre de 1807. Albornoz, Visita, 1987, pp. 161-190.

14 "Representación del regente que fue de la Real Audiencia de Caracas, el señor don Antonio López
Su apreciación era totalmente diferente a la de Mosquera. La iniciativa de los "primeros hombres de la capital" era una expresión más de su inquebrantable lealtad a la corona en esos días aciagos para la monarquía española.

En su concepto, algunos "faccionarios de los enemigos de vuestra majestad" han divulgado la opinión de que una vez formada la junta, "se degradaría la autoridad del gobernador, serían los oficiales y batallones de pardos despojados de las insignias y de las armas, marcados los negros en la frente y otras cosas tan desatinadas como estas". ${ }^{15}$

Fueron estas especies las que movieron el celo del gobernador, lo desviaron de su atención y lo llevaron a adelantar un procedimiento que podrían traer "funestísimas consecuencias" para la provincia al someter a prisión a personas de las familias más ilustres de la capital.

Su recomendación era que se nombrara, cuanto antes, un gobernador y capitán general que fuese un individuo de alta graduación en el ejército y de conocida rectitud, prudencia y firmeza ya que, desde el fallecimiento del mariscal de campo don Manuel Guevara y Vasconcelos, había recaído el gobierno de estos territorios en manos del cabo subalterno coronel don Juan de Casas quien "cansado y oprimido de la edad y continuos achaques de la salud, le privan de aquella energía constancia y discernimiento sumamente necesarios en las delicadas circunstancias de Europa y de las Américas". ${ }^{16}$

de Quintana, 28 de noviembre de 1808", Conjuración, 1968, p. 733.
${ }^{15}$ Ibid.
16 Ibid., pp. 732-733. 
No había pues, a juicio de Quintana, el menor motivo para adelantar un procedimiento como el ejecutado por Mosquera.

El teniente de gobernador y auditor de guerra, don Juan Jurado, coincidía con el parecer de Quintana respecto a las actuaciones adelantadas por Mosquera. El alto funcionario consideraba que siendo un episodio de fácil expedición había sido tratado equivocadamente por el capitán general quien se había dejado abandonar por los consejos del regente visitador.

El regente Mosquera, a juicio del teniente de gobernador, era un hombre impetuoso, odiado y

generalmente temido por su genio adusto, inaccesible y absolutamente impropio de gobernar en circunstancias en que más se necesita prudencia, disimulación y modo para distraer los ánimos y conducirlos a la razón, utilidad y conveniencia. ${ }^{17}$

Explicaba Jurado que la proposición de la junta hecha por los principales tenía su origen en la propuesta del capitán general en julio pasado y que nunca pudo extinguirse del todo el proyecto, ya que las personas notables estaban persuadidas de que era el único arbitrio que quedaba a estas provincias para conservarse en su dependencia de la metrópoli y evitar los daños que podían originarse por la incapacidad y achacosa condición del gobernador. ${ }^{18}$ Fue ello lo que los animó a elaborar la representación que promovía la constitución de la Junta.

17 "Representación del teniente gobernador auditor de Guerra don Juan Jurado", 29 de noviembre de 1808 , en ibid., p. 812.

1 is lbid.
No se le escapaba que la propuesta podía ser considerada riesgosa e inoportuna y así se lo había hecho saber a sus promotores; sin embargo, en atención a que las diligencias se encontraban muy adelantadas, él mismo se había reunido con el capitán general y acordaron admitir la entrega de la representación para someterla a la consideración de la Real Audiencia y de esa forma buscarle una solución a la propuesta.

Este acuerdo había sido desconocido por Mosquera quien

ejerciendo su acostumbrado imperio sobre don Juan de Casas e infundiéndole pánicos terrores formados por cabezas débiles y atolondradas, se posesiona de su persona, se encierra con ella, llama en su auxilio a las que no podían contradecirle, forma acuerdos ilegítimos, previene tropas, conmueve a todos, procede, y sin dejar dormir, ni descansar a nadie en toda la noche, decreta y ejecuta arrestos y prisiones de títulos, empleados y personas, las más notables del pueblo. ${ }^{1 "}$

Si se hubiese obrado de manera más prudente, con más discreción y tino, tomando en consideración las condiciones del país, "cuyos habitantes son tan fáciles de acalorarse, como de moderarse", no se habría llegado a la difícil situación promovida por Mosquera.

Lo que más preocupaba a Jurado eran las consecuencias que podrían desencadenarse del arbitrario proceder de Mosquera. Un primer punto sensible al funcionario español era la ofensa que se había perpetrado contra los vecinos de más alta jerarquía, cuyas "conexiones por sangre, empleos, riquezas y demás circunstancias,

19 Ibid., pp. 813-814. 
interesan a todos los habitantes de las diferentes clases". ${ }^{20}$

Se trataba de un vejamen, de un escándalo público contra los más prestigiosos vecinos de la ciudad, de una ofensa contra el honor, lo que más teme perder un hombre de bien. Se preguntaba, entonces:

¿Qué podrán esperar estos personajes de un gobernador que sobre un hecho como el actual ha procedido a tan notorio ultraje? ¿Qué necesidad hubo para este escándalo en circunstancias tan delicadas, después de haber manifestado este pueblo tanta fidelidad al rey Fernando: tanto odio y aborrecimiento a los franceses? $?^{21}$

La conclusión a la que llega Jurado es terminante. Los abusos cometidos por Mosquera, la ofensa contra el honor de los blancos principales podrían conducir a la peor de las situaciones: la independencia de España:

Muy sensible me es decir a vuestra majestad que esta extraordinaria ocurrencia tiene o puede tener resultas perniciosas en estas provincias porque aunque estas gentes aparentan sufrimiento, y moderación, hay muchos que piensan y nutren ideas muy opuestas a las antiguas, y como por su situación geográfica les es fácil comunicar a los extranjeros, y estos no pierden ocasión de desacreditar el gobierno español, ni de pintar el suyo como más equitativo y justo, esparciendo especies halagüeñas de libertad y seguridad, apurarán las sugestiones, y dispondrán los ánimos hasta lograr el fin de romper la dependencia, y franquearse por este medio un

20 Ibid., pp. 814-815.

${ }^{2}$ Ibid. comercio y comunicación general a que siempre han aspirado, émulos de la rique$z a, y$ abundancia, fertilidad y bondad de las posesiones españolas. ${ }^{22}$

Su recomendación era proceder, inmediatamente, a subsanar el daño causado por Casas y Mosquera, restablecer la confianza de los vasallos, limpiar la mancha que se les había irrogado y garantizar justicia y prudencia en el gobierno, eligiendo a un nuevo gobernador y un nuevo regente de prudencia y conocimientos acreditados.

También los ministros de la Real Audiencia, José Bernardo de Asteguieta y Felipe Martínez de Aragón, coinciden con Antonio López de Quintana y Juan Jurado al recomendar la salida de Casas y Mosquera del gobierno de la provincia.

Tanto Asteguieta como Martínez de Aragón habían sido objeto de severas denuncias en el informe presentado por Mosquera sobre el funcionamiento y los desarreglos en la administración de justicia de la Audiencia de Caracas y el mismo Mosquera los había excluido de manera explícita en las diligencias judiciales para atender la propuesta juntista de noviembre.

Era este aspecto el motivo fundamental de la representación firmada por ambos oidores y remitida a las autoridades que actuaban en nombre del rey en la península.

Denuncian que en todas las diligencias adelantadas por el regente Mosquera se les había excluido, constituyéndose una sala extraordinaria compuesta por el regente, el gobernador y uno solo de los ministros de la Audiencia, don Antonio Julián Álvarez. La actuación constituía una arbitrariedad, se había levantado a título

22 Ibid., p. 816. 
de sala extraordinaria un nuevo tribunal colegiado cuyos votos quedaban reducidos al del regente interino, ya que el gobernador no tenía voto y era un sujeto débil que no hacía sino firmar lo que Mosquera le presentaba y, en el caso de Álvarez, ocurría exactamente lo mismo, en virtud de que se encontraba subordinado por entero a la voluntad de Mosquera.

Con esta manera de proceder se colocaba en un "lastimoso estado de depresión y vilipendio" al tribunal supremo de la provincia erigido con el propósito de atender a los "vasallos oprimidos y quejosos que en estos remotos países no tienen otra confianza ni recurso".

En unos momentos tan difíciles, calamitosos y angustiados como por los que atravesaba la provincia, añaden los ministros, no podían ser

la violencia y negación de todo recurso el remedio de calmar y tranquilizar cualquiera inquietud que se asome, sino la prudencia, la rectitud y el temperamento de las providencias oyendo a las partes agraviadas y quejosas, para que no se piense que en algo se falta a la buena administración de Justicia o que esta se ha convertido en abuso de la fuerza armada. ${ }^{24}$

Concluyen los magistrados manifestando su preocupación por los procedimientos de Mosquera los cuales, lejos de tranquilizar los ánimos y contribuir a la

23 "La Real Audiencia de Caracas informa a vuestra majestad el estado en que se halla esta ciudad, por los procedimientos del coronel graduado cabo subalterno gobernador interino don Juan de Casas y regente interino don Joaquín Mosquera y Figueroa", 12 de diciembre de 1808 , en ibid., p. 742.

${ }^{24}$ Ibid., p. 744 . unión y tranquilidad de los súbditos, no habían hecho otra cosa que promover la inquietud y división del pueblo, generando las más diversas opiniones y susurros, tal como se desprende del fragmento que sigue a continuación:

Unos juzgan que don Joaquín Mosquera y Figueroa es el que aquí tiene poder para hacer cuanto quiera, y temen de la fogosidad de su genio ser sorprendidos y atropellados de la noche a la mañana por cualesquiera rumor, chisme, o ligera sospecha. Otros, que el gobernador don Juan de Casas está gobernado por él, y persuadido de que estas operaciones lo acreditarán y le servirán de mérito para la propiedad del gobierno que anhela. Allí se habla de la honestidad de la pretensión de la junta, de la inocencia de los suscritos, y de los medios legítimos con que la propusieron y pidieron al jefe. Aquí la reputan por una maldad disfrazada que terminaba al abatimiento de los forasteros y gentes de castas, engendrándose por consiguiente desconfianza, desamor y desunión entre las clases del pueblo, que puede traer malas resultas. Aquel dice, que las casas y familias van a quedar difamadas para siempre y confundidas en la última plebe. Estotro pasa a creer que es un despotismo y tiranía lo que se ha ejecutado y una grave difamación la que se les ha irrogado, siendo vasallos fieles que se han movido por el honor y el patriotismo. Cada uno tiene, a su modo, razón en qué fundarse, y todo fluctúa en oscuridades y temores. ${ }^{25}$

El comentario de los ministros traduce el ambiente de confusión, incertidumbre e intranquilidad que se vivía en la provincia, donde todo se encontraba trastor-

${ }^{25}$ lbid. 
nado y cada quien interpretaba los sucesos de acuerdo a sus particulares intereses, desarticulando el buen orden y la armonía que debían mantenerse en una situación tan sensible como la que padecía la España toda.

Para los dos altos funcionarios, lo saludable era proveer las plazas vacantes de gobernador y regente con sujetos de acreditada prudencia y de carácter pacífico, sano y amante de la tranquilidad de los pueblos.

Los ministros de la Audiencia, expresamente excluidos del caso por Mosquera -al igual que Antonio López de Quintana y don Juan Jurado, estos últimos denunciados por Mosquera de estar en combinación con los conjurados-, disienten abiertamente del juicio y actuaciones del regente Mosquera y rechazan las medidas extremas tomadas contra las personas más distinguidas de la sociedad provincial.

La confrontación deja ver las intrigas y desavenencias internas que dividían a las autoridades de la provincia como consecuencia de la visita de Mosquera quien había puesto al descubierto vicios y corruptelas que comprometían a jueces y vecinos. Pero también, y esto es mucho más importante, la diversidad de pareceres que divide a los altos funcionario peninsulares es expresión de los conflictos ideológicos y políticos que desató en todo el imperio español, de uno y otro lado del Atlántico, el descalabro de las instituciones de la monarquía y el desmantelamiento de las bases políticas del antiguo régimen.

En el fondo del debate, lo que está en juego es el tema controversial y crucial del momento político: sobre quién recae la soberanía en ausencia del rey. Para Mosquera no había materia alguna qué discutir, había unas autoridades en España y su legitimidad no era asunto que ameritara mayor discusión, por lo tanto, la propuesta de la junta era un acto subversivo cuyo propósito era obtener la independencia. Sin embargo, Quintana y Jurado se hacían eco de la posición contraria al estimar que la propuesta de la junta se correspondía con lo ocurrido en España, de forma tal que los vecinos honrados y notables de la ciudad, para resguardar los derechos de Fernando, habían tomado la iniciativa de constituirse en junta, o lo que es lo mismo, de asumir la soberanía en nombre del monarca. Tal era lo que había motivado la propuesta juntista de noviembre.

También les preocupa las consecuencias que podría acarrear la arbitrariedad de Mosquera en el sometimiento de los principales y sus efectos sobre la estabilidad política de la monarquía. Los rumores del bajo pueblo, la intranquilidad general, el vejamen al que se había expuesto públicamente a lo más granado de la sociedad provincial, podrían tener efectos nocivos para la integridad del imperio.

Cada uno de ellos, tanto Mosquera como quienes disienten de su proceder e inclusive los promotores de la junta están animados por un mismo objetivo político: preservar el orden monárquico y evitar alteraciones en la provincia. Es esta misma motivación la que inspira a los fiscales encargados de elaborar la sentencia en la cual se absuelve de culpa a todos los implicados en el movimiento.

\section{LA ABSOLUCIÓN DE LOS JUNTISTAS}

Luego de casi tres meses de diligencias y averiguaciones, se produce el primer fallo el 18 de febrero de 1809. La decisión 
es dejar en libertad a la mayoría de los firmantes; la sentencia absolutoria hacía clara manifestación de "no haberles perjudicado a su honor y estimación". En el mismo acto se decide levantar cargos solamente contra "Ios más culpables", estos eran: el marqués del Toro, José Félix y Juan Nepomuceno Ribas, Mariano Montilla, Nicolás Anzola, José de Tovar, Pedro Palacios y Antonio Fernández de León quien, en la segunda semana de diciembre, había sido embarcado para España y puesto a la orden de la Junta Central. ${ }^{26}$

Dos meses más tarde, el 20 de abril de 1809 , se produce el último fallo de los fiscales, don Antonio de Berríos y Francisco Espejo. La recomendación de los funcionarios es sometida a consideración por los miembros de la sala extraordinaria: Mosquera, Casas y Álvarez y admitida por estos el 4 de mayo de 1809 .

El alegato de los fiscales concilia las partes en disputa: avala las medidas tomadas por las autoridades $y$, al mismo tiempo, absuelve de todos los cargos a los "más culpables".

Estimaban los fiscales que Mosquera había actuado en correspondencia con su obligación de mantener el buen orden, la paz y justicia de los vasallos, por lo tanto, la iniciativa de formar sala extraordinaria para atender la novedad había estado sujeta a las graves circunstancias de la provincia.

No se les imputaba ningún delito a los acusados, pero se les recriminaba su "imprudencia e indiscreción". Estimaban los fiscales que la propuesta de constituir una junta había sido inoportuna y de absoluta inutilidad, después de que los puep. 273

26 "Decreto", 18 de febrero de 1809 en ibid., blos de este distrito se habían subordinado a la Suprema Junta de Sevilla. En consecuencia, no podía el intento "dejar de calificarse por una infracción del religioso acto del reconocimiento"; tampoco se podía disfrazar la tentativa con la investidura de su subordinación a la de Sevilla, ya que una novedad tan grave "induciría en todo caso la más peligrosa mudanza y trastorno en el orden Monárquico de nuestra constitución". 27

El planteamiento, por lo tanto, era extemporáneo, máxime cuando en España para evitar los riesgos e inconvenientes que podrían seguirse de continuar dividida la soberanía en tantas juntas provinciales, se había constituido la Suprema Central a la cual quedaban sometidas todas las juntas españolas y todos los dominios de las Indias.

Así, los fiscales se pronunciaban de manera inequívoca respecto al tema de la soberanía, origen de la formación de todas las juntas españolas y de la iniciariva animada por los notables de Caracas. Pero no concluían, como Mosquera, en considerar que la propuesta tenía como objetivo alcanzar la independencia.

La ocasión era propicia para incorporar una reflexión cuya finalidad era advertir los peligros adicionales que la formación de una junta podría acarrear en la provincia de Caracas, como en el resto de las provincias americanas. La composición social de los pueblos de América y las rivalidades existentes entre los españoles, de uno y otro hemisferio, hacían del todo inverificable la constitución de un cuerpo en el cual pudiesen conciliarse las opuestas parcialidades y voluntades que debían con-
"Fallo de los fiscales Berríos y Espejo", Caracas, 20 de abril de 1808 , en ibid., p. 321. 
currir a la constitución de una Junta como la propuesta:

Emulas las unas de las otras, jamás querría la de los nobles admitir en su concurrencia a los del estado llano, ni estos a la clase de los pardos, ni ninguno de ellos a las otras castas y menos a la de los esclavos: esta diferencia de colores produciría un choque violento, con que se destruirían las partes entre sí, antes de formar el todo. $Y$ de aquí es de inferir, que el resultado de la pretendida junta, cuando se hubiese acercado más a su verificación, nunca había sido otro que la ruina de sus mismos agentes, el trastorno de la Constitución nacional, y al fin una cruel anarquía, destructora de todos los bienes sociales, y origen de cuantos males son imaginables en el orden moral y civil. ${ }^{28}$

Era pues, esta peculiar composición y los inevitables antagonismos que se derivaban de la diversidad social y racial de los americanos y, en particular, de la provincia de Caracas, lo que había motivado la pronta intervención de las autoridades, a fin de evitar que la turbación e intranquilidad que se habían esparcido entre las diferentes clases del pueblo pudiesen conducir a una sangrienta conmoción en la ciudad.

La preocupación de los fiscales, ante la eventual disolución que podría desatarse en la provincia de prosperar la erección de la junta, obedecía al diagnóstico que habían elaborado sobre la compleja y sensible diversidad social de la provincia, también era producto de la reacción que la propuesta había generado entre algunos oficiales del batallón de pardos de la capital y de los granaderos de los valles de Aragua y Valencia quienes, el mismo día

${ }^{28}$ Ibid., p. 323.
24 de noviembre, se dirigieron al capitán general reprobando enfáticamente el movimiento. Decía así la representación firmada por los oficiales pardos:

Que por voces muy públicas aunque vulgares han llegado a comprender que ciertos espíritus mal contentos con el suave y dulce gobierno que rige esta bella parte de las posesiones del mejor y más desgraciado de los monarcas, intentan o han intentado alterar en esta época el método gubernativo bajo cuyos auspicios hemos disfrutado hasta el día la mayor tranquilidad, cuando la península en días han tenido su asiento nuestros soberanos se ve inundado de arroyos de sangre defendiendo una dulce causa sin ser trascendental a este continente sino solamente llorar esta catástrofe, pretenden pues estos incautos establecer una junta en esta capital subalterna ( $y$ quién asegurará si independiente?), de la exigida y confirmada por nuestro amo y señor don Fernando VII, que examinado su plan por este gremio de estúpidos que representa, no tiene ni aun el más remoto viso de legal cuando no ha habido un ejemplar semejante en la Europa, o diremos mejor, un atentado tan escandaloso y contrario a los principios de nuestra ley y religión. ¿Y será posible señor capitán general que a la edad futura se cuente que la ciudad de Caracas desentendida ya de la fidelidad y patriotismo de que se ha dado siempre tantas pruebas, se vea ya próxima a dar el paso a su exterminio cubriéndose de un borrón que no lavará ni con su propia sangre? ${ }^{24}$

${ }^{20}$ Pedro Arévalo, Carlos Sánchez, Francisco Javier León, Juan Antonio Ponte, Francisco José Colón "Comunicación al capitán general", 24 de noviembre de 1808, en ibid., pp. 114-115. 
Dispuestos a no permitir que prosperara "ese borrón", manifiestan su firme disposición a enfrentar el atentado de esos "incautos" y se ofrecen para combatirlo como una

PARDA fiera que al lado de vuestra señoría o de quien representa la persona del soberano y sus sabias constituciones llevará entre sus garras tantas presas, cuantas sean las cabezas de los que por su desgracia quieran atentar contra su persona y sabias disposiciones. ${ }^{30}$

La confrontación era clara y sin eufemismos. El documento, aun cuando va firmado por cuatro particulares, se hace en nombre de "los pardos" y contra los principales de la ciudad. Era una declaración de guerra motivada por un tema sensible en lo político, pero inevitablemente la confrontación expresaba también la tensión social entre los pardos y los blancos criollos. De manera que, la preocupación de los fiscales y sus prevenciones respecto a la irrupción de un conflicto de mayor entidad, no eran infundadas.

Sin embargo, los fiscales, a diferencia de los pardos, no se hacían eco de la "voz popular" que había circulado por la ciudad según la cual la junta era tan sólo un pretexto para "trastornar el orden constitucional, despojar a las autoridades legítimamente establecidas, darles muerte, degollar a los españoles europeos y asesinar a las dos cabezas primeras de la provincia".

Era sencillamente inverosímil que en una "ciudad culta" se abrigasen tan monstruosos excesos y menos aún que estos proviniesen de "unos sujetos de obligaciones

30) Ibid, p. 115. tantas, por su educación, por su cuna y sus empleos".

En conclusión, se trataba de rumores populares referidos por los testigos, cuyo apoyo se sostenía "sobre pasajes y atestaciones singulares, en términos susceptibles de error, equivocación y mala inteligencia, y todos referentes a voces vagas del pueblo, siempre fácil y ligero en sus juicios". 31

No había, pues, mayor fundamento en acusaciones cuya procedencia era la "ligereza" de juicio del pueblo en contra de un grupo de prestigiosos vecinos, merecedores de respeto y consideración en atención a su origen, caudal e ilustración, aun cuando estuviese presente la amenaza de guerra de los pardos.

Difícilmente podían los fiscales decidir el desenlace del conflicto prestando atención preferente a los pareceres y susurros del pueblo o dando mayor beligerancia a las exigencias de los pardos. La trayectoria de fidelidad demostrada por los blancos criollos y los comerciantes españoles tenía mayor peso en la decisión de ambos funcionarios, más próximos a los principales en sus pareceres y actitudes que a los miembros de las clases inferiores de la sociedad

La sentencia era, pues, absolutoria y decía así:

En consecuencia de todo y después del más maduro examen, concluyen los fiscales expresando que su dictamen es se corte la causa en el presente estado, dándose por suficientemente compurgadas las gestiones de indiscreción y falta de prudencia, que resultan en la pretensión de la junta por todos los sujetos que la promovieron, con la detención de unos, y arrestos de los otros: que

${ }^{31}$ Ibid., p. 336. 
en su virtud y por consideración a la difamación que los arrestos irrogan a las personas de honor cuando proceden de causa grave, con apariencias de crimen de estado, cuyo aspecto tuvo la presente, se sirva vuestra alteza hacer a favor de ellas la declaratoria conveniente de no deber obstar a su reputación, honor $y$ concepto de fieles $y$ honorables vasallos ninguno de los anteriores procedimientos, y que sin embargo de ellos, quedan íntegramente mantenidos en su buena opinión crédito y fama, sin que en lo sucesivo les sea tampoco obstáculo para obtener las gracias y mercedes que fuere servido el rey concederles, por sus anteriores servicios, y los que espera continúen a beneficio del estado y de la patria, en las calamitosas circunstancias que más necesitan de buenos y amantes vasallos. ${ }^{32}$

En la decisión de los fiscales, se les recriminaba a los juntistas la indiscreción e imprudencia que habían tenido al promover la junta, pero no se les condenaba por delito alguno. En respuesta al vejamen que constituía el escándalo suscitado por las prisiones y confinamientos, se hacía una declaración formal en relación con el sensible tema del honor, aspecto sobre el cual había insistido Juan Jurado cuando manifestó su disidencia contra las medidas que vejaban a los juntistas. Así quedaba resuelto judicialmente el episodio que había generado no solamente la prisión de los más importantes miembros de la sociedad provincial, sino que, además, había movilizado la opinión del bajo pueblo pronunciándose públicamente contra "los padres de familia".

El regente Mosquera, a pesar de haber sido el más pugnaz adversario de los jun-

${ }^{32}$ Ibid., p. 337. tistas, aceptó el fallo de los fiscales, junto con los otros miembros de la sala extraordinaria. En el informe definitivo sobre los hechos, fechado el 20 de junio de 1809 , justifican su proceder y dan cuenta de los efectos positivos que tuvieron las medidas adoptadas. En opinión de los responsables de la causa "después de las prisiones se notaba una tranquilidad y serenidad en la ciudad que no se había gozado en los días antecedentes". ${ }^{33}$ No podía considerarse entonces un exceso cuando había producido tan buenos resultados. Solicitaban, en consecuencia, se aprobara todo cuanto se había practicado en el asunto. Finalmente, declaraban que "sacrificaban al silencio" las mortificaciones que a lo largo del proceso les habían ocasionado a algunos de los procesados; la prudencia con la cual actuaban era una expresión más "del amor al servicio de vuestra majestad" y de la decencia que exigían estos casos. ${ }^{34}$

En ninguna de sus partes el informe de Mosquera expresa algún tipo de comentario o disensión respecto a la sentencia del 4 de mayo. Con el fallo definitivo de los fiscales aprobado por la sala extraordinaria se salda de una vez por todas el conflicto que enfrentó a los vecinos principales de la ciudad con las principales autoridades de la provincia; se dirimieron las diferencias que habían separado a estas en el tratamiento de la causa y se dejaba libre de culpas a los promotores del episodio. De esta manera se procuraba tranquilizar a las partes y se aspiraba que no hubiese mayores perturbaciones en la ciudad, suficientemente intranquilizada debido a las andanzas de los principales.

33 "Informe de la sala extraordinaria", 20 de junio de 1809, en Vejarano, Orígenes, 1925, p. 29.

${ }^{34}$ Ibid., p. 105. 
Pero también la sentencia le salía al paso a los rumores y susurros del pueblo contra los sujetos de mayor prestigio y jerarquía de la ciudad. La absolución de los prisioneros dejaba claro que los miembros de las familias principales gozaban de la confianza de las autoridades y debían seguir siendo estimados en su honor por el resto de la sociedad. No estaban dispuestos ni los fiscales ni los miembros de la sala extraordinaria a favorecer un ambiente de disolución social que pusiese en peligro el orden de la sociedad, aspecto fundamental en la preservación de la estabilidad política y social de la monarquía.

\section{Comentario final}

El movimiento juntista de Caracas promovido por los vecinos principales de la ciudad en noviembre de 1808 fue, como otros proyectos y tentativas juntistas, un acto de fidelidad a la monarquía, aun cuando las historiografías nacionalistas, en su mayoría, lo han interpretado como iniciativa independentista, al igual que lo hicieron quienes persiguieron o sometieron a los juntistas americanos.

En el caso de Caracas, a diferencia de lo que ocurrió en otros lugares de América, los juntistas no fueron sometidos, pero sí juzgados y absueltos, como ya se dijo. Sin embargo, llama la atención la diversidad de pareceres respecto a la valoración del movimiento por parte de las autoridades que tenían a su cargo la dirección política y militar de estos territorios. Para unos se trató, sin duda, de un movimiento que pretendía la independencia, para otros, de un acto que tenía como propósito salirle al paso a la crisis política que atravesaba el reino y garan- tizar la autoridad del monarca depuesto mientras regresaba al trono. Los fiscales, aun cuando no desautorizaron los procedimientos adelantados por los primeros, coincidieron con los segundos al considerar que no se había cometido ningún delito y que, en el peor de los casos, se trató de una indiscreción inoportuna. No se dudó, pues, de la lealtad de los vasallos, por tanto se los absolvió sin que tuviese consecuencias en su honor, un aspecto sensible e importante en el orden antiguo.

A pesar de las diferentes apreciaciones y actuaciones que se advierten en los sucesos ocurridos en Caracas durante el año de 1808 , existe una uniformidad de propósitos entre quienes se ven involucrados en el conflicto. Tanto los promotores del movimiento juntista de noviembre como las autoridades - las más recalcitrantes y las más moderadas- actúan movilizados por un mismo objetivo: preservar el orden monárquico y evitar alteraciones ruinosas para la provincia; lo mismo podría decirse de los pardos cuando se oponen y rechazan la iniciativa de los mantuanos.

Todos actúan movidos por el deseo de evitar que se rompa la estabilidad política de la provincia. Los vecinos principales consideran que la junta sería el mecanismo para evitar la desintegración de la monarquía. Por su parte, Mosquera actúa a fin de impedir que pueda ocurrir una alteración en el orden y estabilidad política en los territorios sujetos a la autoridad del reino. Quintana, Jurado, Martínez y Asteguieta estiman que los procedimientos de Mosquera podrían provocar una peligrosa desunión entre las autoridades peninsulares y los vecinos principales rompiendo así el equilibrio político y la paz en la provincia. Por último, los pardos reaccionan para impedir que los blancos mo- 
dificasen "el método gubernativo bajo cuyos auspicios hemos disfrutado hasta el día la mayor tranquilidad". Así, por razones distintas y movilizados por razonamientos diferentes, todos actúan con una misma intención: preservar el orden monárquico y evitar desórdenes y alteraciones en el gobierno provincial.

El fallo absolutorio de los fiscales, el cual es admitido por la sala extraordinaria, logra conciliar las partes y tiene como resultado evitar el estallido del conflicto y mantener la estabilidad política en estos territorios. Sin embargo, muy poco tiempo después, en abril de 1810 , se planteará nuevamente la constitución de una junta en la ciudad, la cual, al igual que en 1808 , sería la depositaria de la soberanía mientras el rey permanecía cautivo. En esta ocasión el desenlace de los acontecimientos tendrá otros derroteros. Un año después, el 5 de julio, se declaró la independencia de Venezuela y se puso fin al orden monárquico en la mayoría de las provincias que formaban parte de la capitanía general de Venezuela. A partir de allí sería el conflicto bélico el que definiría el futuro de estas provincias y el fin del orden monárquico en el resto del continente americano.

\section{BIBLIOGRAFÍA}

-Albornoz de López, Teresa, La visita de Joaquín Mosquera y Figuerna a la Real Audiencia de Caracas (1804-1809): conflictos internos y corrupción en la administración de justicia, Academia Nacional de la Historia, Caracas, 1987.

- Anna, Timothy, España y la independencia de América, FCE, México, 1986.

-Artola, Miguel, La España de Fernando VII, vol. XXvi, Historia de España por Ramón
Menéndez Pidal, Espasa Calpe, Madrid, 1968.

Antiguo réginnen y revolución liberal, Ariel, Barcelona, 1978.

-Blanco, José Féliz y Ramón Azpúrua, Documentos para la vida pública del libertador, Ediciones de la Presidencia de la República, Bicentenario del Libertador, Caracas, 1977, xv vols.

-Bulnes, Gonzalo, 1810. Nacimiento de las repúblicas americanas, Juan Roldón y Cía., Buenos Aires, 1927, 2 vols.

-Conjuración de 1808 en Caracas, Instituto Panamericano de Geografía e Historia, Caracas, 1968.

-Chust, Manuel, La eclosión juntera en el mundo bispano, Fideicomiso de las Américas-FCF, México, 2008.

-Gil Fortoul, José, Historia constitucional de Venezzteld, Las Novedades, Caracas, 1942, 3 vols.

-Guerra, François-Xavier, Modernidad e independencia, MaprRe, Madrid, 1992.

-Lynch, John, Las revoluciones hispanoamericanas. 1808-1826, Ariel, Barcelona, 1985.

-McKinley, Michael, Caracas antes de la independencia, Monte Ávila Editores Latinoamericana, Caracas, 1993.

- Parra Pérez, Caracciolo, Historia de la primera repíblica, Academia Nacional de la Historia, Caracas, 1959, 2 vols.

-Quintero, Inés. La conjura de los mantuanos. Último acto de fidelidad a la monarquía española, Universidad Católica Andrés Bello, Caracas, 2000.

-Rodríguez, Jaime, La independencia de la América española, Fideicomiso de las AméricasFCE, México, 1998.

- Vejarano, Jorge, Orígenes de la independencia surantericana, Cromos, Bogotá, 1925.

-Yanes, Francisco Javier, Compendio de la historia de Venezuela, desde su descabrimiento basta que se declaró estado independiente, Academia Nacional de la Historia, Caracas, 1944. 